\title{
Hacia un nuevo clero en los Andes a finales del siglo XVIII: la ordenación A título de lengua en el Arzobispado de Lima
}

\author{
por \\ Bernard Lavallé \\ Université de la Sorbonne nouvelle-Paris III
}

En el arzobispado de Lima, como en otros, a finales del siglo XVIII se nota un cambio sustancial en el reclutamiento del clero secular para las doctrinas. Se privilegia entonces a los lenguaraces, conocedores de la lengua indígena, pasando ese requisito por encima de los demás. Eso tuvo consecuencias notables sobre la preparacion pero también el origen social y étnico de esos sacerdotes, obligados a trabajar con estatuto fragilizado, sin posibilidad de promocion ni cambio de destino, desembocando todo eso en la aparicion de un verdadero bajo clero.

Palabras Claves: Doctrinas; bajo clero; clero indigena; mestizos.

En el clero secular colonial, el acceso a las sagradas órdenes suponía por supuesto el cumplimiento de ciertas condiciones previas. Había, por una parte, el examen de la formación intelectual, de los conocimientos teológicos y eclesiásticos de los candidatos. Por otra, se diligenciaba una especie de investigación encargada al cura del que era feligrés el futuro ordenando. Esa pesquisa no debía revelar ningún impedimento en cuanto a «las buenas costumbres», y se requería averiguar que la persona en cuestión había nacido dentro de una unión legítima de «cristianos viejos, limpios de toda mala raza de herejes, moros, judíos y de los recién convertidos a nuestra santa fe», fórmula que de manera evidente procedía directamente del rancio prejuicio hispano de la limpieza de sangre.

El candidato a ordenante también tenía que justificar que poseía medios de subsistencia que le aseguraban una renta anual de por lo menos 200 pesos, la llamada congrua sustentación. Dicha renta provenía a menudo de un patrimo- 
nio constituido por una herencia, una donación de los padres, de algún familiar o persona cercana. Dado el sistema de cálculo entonces vigente (esto es una rentabilidad del 5\%), esta exigencia correspondía a una fortuna de por lo menos 4.000 pesos. En este caso, la persona era ordenada a título de patrimonio. La realidad de esos bienes era comprobada y certificada por documentos notariales en los que se daba una constancia oficial de su existencia y valor, a veces de manera muy pormenorizada, y esos papeles se adjuntaban a la solicitud del candidato. En el caso, además frecuente, de que la propiedad del ordenante sólo se hiciese efectiva a la muerte de sus padres o de los donantes, éstos se comprometían mientras vivieran a abonar a su hijo la renta correspondiente a la cantidad declarada.

El mínimo de los doscientos pesos anuales se podía garantizar también con el servicio de una o varias capellanías instituidas por piadosos testadores preocupados por el eterno descanso de su alma (que figuraba entonces entre los herederos oficiales) y/o deseosos de asegurar la subsistencia, generación tras generación, de algún miembro de su descendencia. La ordenación se hacía entonces a título de capellanía. Esas capellanías consistían en la celebración de cierto número de misas cada año. Se calculaba entonces su monto, y el del pago correspondiente, en función de la cantidad prevista de misas cantadas o rezadas (de valor diferente) que se habían de celebrar y abonar sobre lo que rentaban los bienes del testador destinados a ese efecto. Ese servicio se cumpliría «perpetuamente». Esto significaba que las capellanías se transferían y heredaban con el paso del tiempo, lo cual comprometía a los sucesores de los testadores, a veces de manera bastante gravosa en la medida en que había capellanías muy pingües y éstas tendían a acumularse generación tras generación.

Sin embargo, ese requisito económico no era absoluto. Cuando no se podía cumplir, a la vez por no desalentar a vocaciones interesantes y no privarse de su colaboración, la Iglesia había previsto que no estaba prohibido ordenar también a candidatos con formación universitaria (abogados, doctores, docentes de diversos niveles, etc.), estudios en colegios religiosos, de comprobada experiencia en la administración, o bien con reconocidas cualidades particulares entre ellas largos servicios en funciones eclesiásticas subalternas (sacristán, organista, catequista, cantor o maestro de capilla, ayudante de cura) que merecían ver premiados de esa manera sus capacidades atestiguadas. Era la llamada ordenación a título de suficiencia ${ }^{1}$.

1 Para más detalles sobre los diversos tipos de ordenaciones, Ganster, 1974: 6-14, y O'Phelan Godoy, 2002: 311-329. 
En el contexto americano colonial, esta última posibilidad se había ampliado a otro tipo de aptitud: el conocimiento de una lengua indígena (era la ordenación a título de lengua), fundamental - e incluso obligatoria según la reglamentación en vigor - para el trabajo en las doctrinas indígenas. Desde fecha muy temprana, los obispos del Perú, como antes de ellos los de Nueva España, habían recurrido a ese tipo de ordenaciones, tanto para candidatos al sacerdocio como para aquéllos que, por lo menos en un primer tiempo, sólo solicitaban las órdenes menores. El tercer concilio de Lima, tan importante y decisivo en las orientaciones definitivas del catolicismo andino colonial, había ratificado de manera oficial esta posibilidad en $1583^{2}$.

En adelante, el manejo de una lengua indígena se encontró en diversas ocasiones en el corazón de debates importantes en el seno la Iglesia peruana. Cuando a finales del siglo XVI los obispos se vieron desbordados por el aflujo de candidatos al sacerdocio a los que no podían dar condiciones de vida decentes por la falta de curatos disponibles, algunos tomaron la decisión de ordenar sólo a título de indios, esto es con el compromiso por parte de los ordenantes de ir a servir alguna doctrina, pero también por supuesto de saber previamente la lengua de sus futuros feligreses.

Este último punto había sido también uno de los argumentos esenciales alrededor de los cuales había girado la primera reivindicación criolla, ya desde la década de 1570. Prácticamente en todo el virreinato, los sacerdotes hijos de la tierra (como entonces se autodefinían) habían comenzado a reclamar el servicio - y los ingresos oficiales o anexos- de las doctrinas hasta la fecha servidas en la casi totalidad de los casos por sacerdotes venidos de la Península. Los criollos consideraban esos cargos como bienes patrimoniales de su tierra que, en virtud de la prelación, viejo principio medieval del derecho eclesiástico hispano, habían de recaer en prioridad en los nacidos en esos obispados, tanto más cuanto que éstos tenían relativamente a los sacerdotes venidos de España la ventaja decisiva de ser lenguaraces, esto es de conocer bien el idioma de los indios pues lo habían manejado desde niños ${ }^{3}$.

Más tarde en el siglo XVII, el debate había de resurgir, a veces de manera bastante acalorada con ese mismo argumento central, cuando los largos y repetidos enfrentamientos entre regulares y seculares a propósito de las doctrinas. Aquéllos, celosos de su independencia frente a los obispos, se negaban a menudo a someterse al examen de lengua indígena con el que debían cumplir los futuros doctrineros ante las autoridades episcopales. Efectivamente, podía ser

2 Para las decisiones al respecto en tiempos del tercer concilio de Lima, Lisi, 1990, y Estenssoro Fuchs, 2003: 261-268.

3 Lavallé, 1993: 63-78. 
para el ordinario una manera indirecta de controlar los nombramientos que las órdenes hacían en dichas doctrinas después de los capítulos provinciales trienales, a menudo en un contexto de mero reparto de las fuentes de ingreso y de retribución entre miembros de un mismo bando, que de consideración del servicio de la evangelización ${ }^{4}$.

\section{LA ORDENACIÓN A TÍTULO DE LENGUA, UNA VÍA ALTERNATIVA Y MINORITARIA}

A comienzos del siglo XVIII, en el arzobispado de Lima la ordenación a título de lengua no era excepcional pero seguía siendo un fenómeno muy minoritario. Lo prueba el que durante los años 1700-1704 el ordinario había aceptado 19 de ellas de un total de casi 190 ordenaciones, o sea apenas un $10 \%$. Medio siglo después, entre 1750 y 1753, ese porcentaje incluso había bajado, ya que sólo se contaron siete (más uno ordenado a título de capellanía y lenguaraz) o sea alrededor de un $8 \%$ del total 5 .

En lo que al último tercio del siglo se refiere, los primeros años (17701775) parecen seguir el mismo camino. De las casi 130 ordenaciones, un poco menos del $40 \%$ se habían aceptado a título de capellanía, y no llegaban al $25 \%$ aquéllas que se habían concedido en vista de una congrua suficiente. Si ninguna presenta como suficiencia el solo hecho de ser lenguaraz, algunas pocas evocan esa especificidad como de añadidura, para compensar una formación teórica o antecedentes de carrera tal vez discutibles y que podrían parecer un poco ligeros. Así, en 1772, un tal Casiano Balcázar, oriundo del valle de Chancay en la costa norte de Lima, presentaba su solicitud:

Hallándo[se]) con instrucción mediana en latinidad y materias morales y expedición en la lengua quichua y edad de más de la necessaria y patrimonio sobrado...

Al año siguiente, Domingo Víctor de la Vega y Rodríguez, de Carhuaz, en el andino callejón de Huaylas, no dudaba de que como las veces pasadas (porque ya había sido rechazado) se iba a argüir en contra de su candidatura su edad (tenía 35 años), la imposibilidad de encontrar su partida de bautismo (lo cual podía infundir sospechas en cuanto a sus orígenes pues era la acostumbrada coartada de aquéllos que querían ocultar algo al respecto) y por fin el hecho

4 Lavallé, 1999: 267-278.

5 La documentación inédita utilizada en este estudio procede de la serie Ordenaciones sacerdotales del Archivo Arzobispal de Lima que hemos analizado sistemáticamente para los años 1770-1799 (legajos 77-96). Como los expedientes están clasificados de manera cronológica, daremos para cada uno el nombre de la persona y el año en que está clasificado. 
de que era viudo de una india. Por lo tanto, y aunque pudiese justificar una $c a-$ pellanía de renta suficiente, insistía primero sobre el peculiar interés para la Iglesia de su eventual colaboración en el clero:

... Y asimismo ser mui esperto el suplicante en la lengua índica que es tan necessaria en este reyno, pues por este título an asendido muchos a los sacros órdenes, demás de gozar suficiente patrimonio para ingressar a los órdenes menores como a mayores.

En la segunda mitad de la década, las ordenaciones a título de lengua continuaron siendo poco numerosas, y eso es tanto más de notar que el total de los candidatos oriundos de las zonas andinas - y por consiguiente predominantemente indígenas - del arzobispado crecía de manera ya significativa. Algunos expedientes revelan además que el problema del servicio de las doctrinas (que incluía pues el manejo de la lengua de los indios) se planteaba en términos ya muy claros. En 1776, Jacinto Pacheco, estudiante pobre (manteista) en el seminario pedía una dispensa por no tener todavía la edad mínima requerida para las órdenes mayores. Aducía para ello la gran y preocupante escasez de sacerdotes en su región natal (Oyón, en Sierra limeña de Cajatambo) y la apremiante necesidad de que éstos fuesen oriundos de esa zona. Hablaba de:

... el interés espiritual de [su] Patria y de los lugares circunvecinos en los que, por la carencia de sacerdotes, es notoria la falta de pasto espiritual así por que los párrocos solos no pueden atender a tanto como por no haver sacerdotes patricios.

En 1777, para apoyar la candidatura de Mariano de Arias y Ulloa, también alumno del seminario de Lima y de la misma procedencia que el anterior ( $d o c$ trina de Churín, en la Asunción de Oyón) el cura de Cajatambo escribió al arzobispo:

Se digne dar sacerdote a esta doctrina por no haver ninguno del lugar, y padecen los havitadores lo que hasta hoy, pues por defiscencia de operarios no está la viña del Señor como devía estar, lo que lastima el corazón.

Ese mismo año, Francisco de Amaya, nacido en Andalucía, en Ronda, donde había sido estudiante antes de pasar al Perú para trabajar un tiempo, como muchos jóvenes peninsulares de la época, en el comercio con un pariente, solicitaba también las órdenes mayores. Aunque podía probar una congrua suficiente, hacía hincapié en que había ayudado en Lima al capellán del hospital de Santa María de la Caridad reservado a las mujeres, y sobre todo que había vivido más de dos años en la Sierra «en cuio tiempo se dedicó al ydioma yndico en el que adquirió perfecta instrucción, lo que hará constar ante cualquier persona que profese esta facultad, si V. S. lo tubiese por conveniente». 
LA FALTA DE SACERDOTES EN LAS DOCTRINAS DE LA SiERRA

Durante la década de los años 1780, las órdenes siguieron mayoritariamente concedidas a candidatos cuya situación material estaba asegurada por une capellanía (casi el $50 \%$ de los casos), gracias a una congrua suficiente (más del 30\%) o aduciendo variadas suficiencias (casi el 10\%).

En cuanto a las ordenaciones a título de lengua, estamos entonces en una época bisagra. Éstas eran todavía más bien excepcionales (menos de una decena) a lo largo de la primera mitad de esa década, pero en los expedientes de los candidatos no sólo menudean ya las alusiones a la falta de curas en las zonas andinas sino que éstas se hacen cada vez más explícitas y apremiantes. Así, Mariano Avellaneda en 1780 habla de «la gran carencia de eclesiásticos que hay en la villa de Pasco donde resid[e]» y de «la copia de fieles que moran en aquellas partes remotas y perecen tal vez sin la administración de sacramentos». En 1785, Josef Pantaleón Malpartida, nacido en la doctrina de San Pedro y San Pablo de Piscobamba (Conchucos) y poseedor de un patrimonio considerable (16.000 pesos) que le permitía vivir muy holgadamente, era sin embargo recomendado por el cura de su doctrina:

por la mucha escasez de sacerdotes en que se alla esta doctrina, que en estos años han fallecido dos que eran los que más serbían de alivio, y oy es mui difícultoso el hallarlos por que aunque en la provincia de Huailas los ai en abundancia, éstos por no dejar su tierra, ni para cuaresmeros, no quieren salir de ella, por lo que hallo por conveniente que al pretendiente se le havilite para que luego benga a serbir en esta doctrina.

Hay que reconocer, sin embargo, que las regiones andinas no eran la únicas en suscitar ese tipo de quejas. En 1780, Josef Mariano Ligero, de Pisco en la Costa Sur, que en un primer tiempo había solicitado las órdenes con «incesante deceo y aplicación», pero falto de congrua, antes de que una persona piadosa se la diera, puntualizaba también en su carta de candidatura que su comarca natal estaba «escasíssima de sacerdotes para el pasto espiritual en circunstancias de ser mui necesarios por la multitud de haciendas abitadas de esclabos y sirvientes para quienes es mui difícil el recurso a lo parroquial, y por eso cualquiera de los que en ella abitan es útil a beneficio espiritual de esa parte de grey».

La mayoría de las veces, los documentos que aluden a ese problema establecen un paralelo entre la gran necesidad de sacerdotes que sepan el quechua y el interés de la Iglesia en ordenar personas de la región, lenguaraces por su origen y que por sus vínculos familiares no tratarán de abandonar su destino para irse a zonas menos apartadas y desfavorecidas, como sin duda pasaba con sacerdotes procedentes de las ciudades. En 1784, Francisco Sánchez, de Hua- 
raz (Conchucos), aunque había estudiado en colegio y gozaba de una renta que le servía su madre, esperaba compensar la ilegitimidad de su nacimiento por el hecho de que su vocación contribuiría a contrarrestar los desastrosos efectos de «la inopia que en aquellos lugares hay de sujetos peritos en el idioma índico y materno para que los señores curas que la ignoran exoneren su conciencia con tener compañeros lenguaraces». El mismo año, Josef María Diestra, de Santo Domingo de Jauja, escribía al arzobispo:

Desde mi tierna edad, por vocación que he tenido al esttado eclesiástico, me he empleado en el estudio de la latinidad, moral y lengua general, a cuyos títulos y el de ser intter en aquellos territorios pido a Vuestra Illustrísima me admita a las sagradas órdenes.

El cura entonces en funciones en esa doctrina, D. Vicente Rubín de Celis, retomaba esos argumentos en una carta de apoyo, y pintaba de manera preocupante las consecuencias de semejante situación que él vivía diariamente:

En aquel territorio ay una conozida escasez de operarios para ayudar a los curas, siendo forzoso, y con no pequeña dificultad, hechar mano de los regulares que muchas vezes no se encuentran porque quizás no es conveniente el desttinarlo, biéndose los párrocos impelidos muchas vezes a estte ocurso por la necesidad que se padeze a recurrir a provincias extrañas de las que se logran sino compañeros por poco tiempo ${ }^{6}$.

Esa solicitud tuvo una respuesta favorable. El arzobispo aceptó ordenar a Josef María Diestra "a título de suficiencia en el ydioma general yndio», y precisó la razón expresa de su decisión: que pasara a ocuparse de dicha doctrina:

... logrando el prettendiente las órdenes ha que aspira, se probee aquella doctrina de un ínter perpetuo como tanto propende ha residir en su territorio.

En 1785, Fernando García y Calvo, de Huaraz, que reconocía no había estudiado mucho, pidió sin embargo ser ordenado a título de patrimonio, lo que finalmente consiguió, pero en su solicitud había expresado lo siguien-

6 Este documento no es el único en que los doctrineros afirmaban sentir mucho la obligación en que se veían de recurrir a ayudantes (compañeros) regulares por falta de seculares (v. por ejemplo, en 1793, el expediente de Luis de Silva Albornoz de Baños, Huamalíes). Era efectivamente un colmo en la medida en que las últimas doctrinas servidas por los frailes habían sido secularizadas a mediados de siglo, en la mayoría de los casos después de largos y duros enfrentamientos. Entonces, entre las razones aducidas por la Corona para sacar a los frailes de las doctrinas, figuraba la acusación de que éstos solían conocer bastante mal el idioma nativo. 
te, pensando sin duda que sería una argumento grato y decisivo para el prelado:

... a efecto de contribuir por mi parte al mejor servicio de Nuestro Señor y bien de las almas, especialmente en las doctrinas de Sierra en las que, sin embargo de ser mucha la mies, los operarios muy pocos ya porque no se acomodan a lo ríjido de estos climas los que no han nacido en ellos, ya porque no entienden ni saben hablar la lengua índica, sin la qual de ningún modo pueden administrar rectamente los santos sacramentos, como experimentadamente lo reconoció Vuestra Illustrísima quando hizo la visita de esta provincia.

El conocimiento del quechua era presentado como una cualidad evidentemente apreciable, por no decir imprescindible, que venía a sumarse a las demás. En 1784, Juan Agustín de Santibáñez, de Hatun Jauja, exalumno del colegio de Huamanga y después de San Ildefonso en Lima, con congrua suficiente, lo exponía claramente. Solicitaba las sagradas órdenes «a título de dicha congrua, además de la qual es recomendable el ser lenguarás en el ydioma yndico». Dicho de otra forma, como en los casos precedentes, se trataba pues de una ordenación hecha a doble título, el goce de un patrimonio o de una $c a$ pellanía, y el conocimiento de la lengua indígena, opción que durante esos años se encuentra algunas veces. En cambio, las ordenaciones fundadas sobre las solas capacidades lingüísticas de los candidatos seguían siendo excepcionales en esa época ${ }^{7}$.

Sin embargo la insistencia de ciertos pretendientes sobre ese aspecto de su solicitud correspondía sin duda al hecho de que el arzobispo lo consideraba ya con más interés y benevolencia que antes, dada la situación preocupante de las lejanas doctrinas serranas. Lo prueba una carta adjunta al expediente de Josef López de Olaz (1783) de San Sebastián de Huaraz. Una persona que escribía, según se solía hacer, para confirmar las buenas disposiciones del candidato, daba por supuesto un parecer muy favorable, y añadía las siguientes consideraciones muy reveladoras «y como la mente de nuestro illustrísimo prelado es ordenar a los de la tierra por rasón de ser lenguaraces...». Del mismo modo, en 1785, el superior del seminario de Lima proponía que se ordenara a tres de sus estudiantes, precisando bien que dos de ellos sabían el quechua. Un año antes,

7 Por ejemplo, en 1786, Mariano Cabanillas, de la doctrina de Santo Domingo, escribía al arzobispo: «Sin otra congrua que la de su piedad y misericordia, asimismo la instrucción en la Lengua me sirve de un apoyo que me hace recomendable por falta de ministros en aquellos lugares y que acaso por esto carecen del mejor conocimiento de los principales rudimentos de nuestra Religión christiana». En 1788, Atanasio Caldas, oriundo de Ambar insistía sobre «su perfecsión y peritia en la lengua o idioma yndico del paíz, no sólo por haverlo aprehendido sino también tenerlo con la primera leche de mi infancia. A este título apreciable, solicito de la piedad de Vuestra Señoría Illustrísima las órdenes sagradas hasta el de presbítero». 
se había mostrado muy severo en cuando a la candidatura de otro de ellos («no da más de sí»), pero a continuación había matizado su juicio en un sentido positivo, insistiendo precisamente sobre su origen y sus aptitudes lingüísticas («es serrano, sabe lengua y puede ser útil»).

\section{LA NUEVA POLÍTICA EPISCOPAL DE ORDENACIONES (1789)}

Esa evolución fue de alguna manera oficializada a finales de la década. Entre octubre y noviembre de 1789 el arzobispo aceptó ordenar a una serie de candidatos pero, cosa nueva, su firma iba acompañada de un texto que precisaba bien las condiciones, y restricciones, de dichas ordenaciones. Demos un ejemplo: a propósito de Juan Amancio Alcayde de Monge, oriundo de Jauja, que no tenía patrimonio ni capellanía pero «esta[ba] bien impuesto en el ydioma índico», el prelado indicaba expresamente lo siguiente en su carta de aceptación:

Admítase en atención a hallarse en esta ciudad los curas de las doctrinas inmediatas al lugar de donde es oriundo, recívasele con éstos la información de vida et moribus, comparesca a examen al tiempo oportuno y haga los ejercicios acostumbrados, haciéndole saber queda obligado a salir de ynter de cualquiera doctrina cada y cuando sea necesario se heche mano de él, lo que hay que executar con toda obediencia y sin escusa alguna, y para evitar inconvenientes que puedan ocurrir sobre este asunto se le hará firmar con el puño la diligencia y se haga constar si está llano a recibir los sagrados órdenes sólo de esta calidad.

Como se ve el arzobispo andaba con cuidado. Justificaba su decisión considerando de manera prioritaria el aspecto lingüístico de la candidatura, pero también tomaba sus precauciones para que, una vez ordenado el candidato cumpliera efectivamente con lo que se esperaba de él por ese motivo. La práctica iba a demostrar, efectivamente, que una vez conseguida la tan ansiada ordenación, algunos de esos lenguaraces tendían a evadirse de su obligación. Trataban de postergar, sin duda lo más posible, su salida para las altas tierras serranas y condiciones de vida sin duda mucho menos llevaderas que las que tenían en Lima.

Así, en 1791, Francisco Pardo pidió una prórroga de un par de meses para ir a reunirse con sus feligreses porque, decía, «están crecidos los ríos que tengo que pasar, cuias crecientes amenasan de aoga en los caminantes y no tener puente de que valerse, lo que me tiene consternado». Otros, no bien estaban en su doctrina, iniciaban trámites para regresar a Lima, como Juan José de Alva, en 1790. Destinado como interino en la doctrina de Santa Inés de Matucana, en la Sierra de Lima, pidió dos veces que se le permitiese volver a la capital, 
según afirmaba para ocuparse de su madre ya anciana y de sus dos hermanas desprovistas de medios de subsistencia. En ambas oportunidades la autoridad episcopal se mantuvo firme y, haciendo hincapié en las condiciones del ordenamiento, como hemos visto explícitamente aceptadas por el candidato, le negó el traslado solicitado.

En adelante, las líneas arriba citadas acompañaban todas las decisiones del arzobispo cuando aceptaba ordenar a alguien a título de lengua. Su resultado fue que no creaban un cuerpo intermediario de doctrineros, pero sí de hecho ratificaba su existencia: el de unos sacerdotes únicamente destinados al trabajo en las regiones indígenas en vista de sus conocimientos lingüísticos, en calidad de ayudantes o adjuntos (se los llamaba tenientes o compañeros del sacerdote titular, o inter - esto es interinos), susceptibles de ser desplazados según las necesidades, que no podían negarse a ir al destino que se les habría indicado y sin perspectiva de carrera ni ascenso. Como se ve, fuera del trabajo en zonas indígenas, esos interinos tenían poco en común con los curas doctrineros, considerados como titulares (ellos decían significativamente propietarios) de su puesto que habían conseguido por concurso (oposición). En los años sucesivos, esta disposición iba a extenderse a otros obispados peruanos, como hemos mostrado hace algunos años en el caso del de Arequipa en el Sur del país 8 .

Otro elemento de notar a propósito de la decisión arzobispal, y prueba manifiesta de su voluntad de orientar de manera significativa la política a seguir en cuanto a ordenaciones se refería: en una serie de aceptaciones firmadas en aquel entonces, todas las que concernían a individuos nacidos en comarcas andinas lo son con la restricción arriba indicada, aun cuando los candidatos gozaban de una capellanía o un patrimonio suficiente que por sí solo habrían autorizado la ordenación. Eran entonces ordenados a doble título, de lengua — primero - y de patrimonio — en segundo lugar — . De esta forma, si bien se reconocía la «normalidad» de su situación material, su primera calificación los designaba de forma automática e ineludible para el trabajo en doctrinas serranas y eso aun en los casos en que no habían insistido en su solicitud sobre su aptitud de lenguaraces.

Un ejemplo: el ya citado Gregorio Miguel Fialo, de la doctrina de Santa Ana de Tarma donde ya había ayudado al cura, ordenado de menores en 1787 a título de una capellanía sobradamente suficiente (6.000 pesos), pero que entonces había insistido en su manejo del quechua, recibió dos años más tarde,

\footnotetext{
8 Lavallé, 1999: 331-354.
} 
en 1789, las órdenes mayores, pero a título de lengua, y con las obligaciones y restricciones arribas indicadas ${ }^{9}$.

Mientras tanto, los candidatos limeños, o más generalmente costeños, seguían siendo ordenados de la misma manera que antes, sin las restricciones y obligaciones impuestas a los andinos desde finales del año de $1789^{10}$.

Esa nueva orientación dada a las ordenaciones seculares no tardó en tener una serie de consecuencias.

Primero, según los documentos conservados en al Archivo Arzobispal de Lima, el número de solicitudes aumentó en notables proporciones. Se pasó de unos 275 expedientes para los años 1780-1789 a casi 450 para la última década del siglo. Entre éstos, los pedidos de ordenación a título de capellanía ya sólo representaban un poco más del $20 \%$ del total, y la a título de patrimonio o de congrua suficiente menos del 10\%. En cambio, las ordenaciones de lenguaraces, unas 240 , superaban el $50 \%$, porcentaje comparable con el que se podía notar en el obispado de Arequipa en la misma época ${ }^{11}$.

Fuera del virreinato limeño, esa evolución también existía, pero al parecer en proporciones y contextos algo diferentes. En esa misma época (1791), David Brading cita un censo del clero secular de Michoacán cuyos resultados son difíciles de comparar con nuestras cifras. Se observa que allí hacia dicha fecha, las 107 ordenaciones a título de idioma (como se decía en Nueva España) eran un poco menos numerosas que las que se habían concedido a título de pura administración en castellano (144) pero seguían rebasando apenas la mitad de las aceptadas a título de capellanía (203)

9 Casos iguales fueron los de Juan Miranda, de la doctrina de Sihuas (Conchucos) que recibió las órdenes menores en 1785 gracias a una capellanía, y fue ordenado sacerdote en 1792 a título de lengua, o el de Francisco Tafur, respectivamente en 1787 y 1792 . Éste es interesante porque era limeño (de la parroquia de San Marceo) e hijos de padres nacidos en España. Antiguo sacristán de la parroquia del Sagrario y de la viceparroquia de los Huérfanos (de ahí su primera ordenación a título de suficiencia) indica que había hecho el esfuerzo de aprender el quechua («con la siempre suficiencia de la lengua yndica que poseo por haverme dedicado a ella») sin duda para poder acceder al estado eclesiástico.

10 Más tarde, en 1799, José de Cárdenas, que tenía congrua suficiente, oriundo del asiento de San Juan de Marcabal en la sierra de Trujillo pero exalumno del colegio de San Ildefonso en Lima, pidió sin embargo su ordenación a título de lengua porque, según afirmaba, el arzobispo había firmado un edicto según el cual los de fuera, esto no nacidos en el arzobispado, sólo podían ser ordenados como lenguaraces.

$11 \mathrm{~V}$. nuestro trabajo aludido en la nota 8.

12 Brading, 1994: 125-126. Es de notar, entre otras dificultades para hacer comparaciones con Lima, que se desconoce el motivo de la ordenación de una proporción importante del clero (126) y que las cifras de Michoacán conciernen sólo a los sacerdotes. 
En el obispado novohispano de Guadalajara las ordenaciones a titulo de idioma conocieron también entonces un notable incremento pero, como advierte William B. Taylor, en un contexto bastante complicado que limitó notablemente el efecto y alcance de la evolución ${ }^{13}$.

Sin embargo, tenemos un buen indicador del atractivo, pero también de las reticencias, que podía suscitar entonces en México ese tipo de ordenación. Cuando el famoso Periquillo Sarniento de Fernández de Lizardi trata, mal que bien y con muchas dudas, de elegir un destino honrado, un amigo suyo le da el siguiente consejo:

... Ordénate a título de idioma; ello es malo, porque los pobres vicarios son unos criados de los curas, tales hay que les hacen hasta la cama, pero esto es poco, respecto a las ventajas que se logran...

Informado de tal perspectiva su padre le recuerda entonces la necesidad de enfrascarse en el estudio de una de las diversas lenguas indígenas, pero sobre todo le pinta de manera detallada, y espeluznantemente caricaturesca, lo que le esperaba en alguna remota doctrina: «... debes ir sin réplica donde te mandare tu prelado, aunque sea al peor pueblo de la Tierra caliente, aunque no te guste o sea perjudicial para tu salud, pues mientras más trabajo pases en la carrera de vicario, tantos mayores méritos contraerás para ser cura algún día» y le citaba a continuación el mucho calor, «la poca o ninguna sociedad si no es de indios mazorrales», las confesiones a todas horas, los soles ardientes, los fuertes aguaceros, las continuas desveladas o vigilias, «los alacranes, turicatas, tlalages, pinotillo, garrapatas, jejenes, zancudos y otro insectos venenosos de esta clase que te beberán la sangre», sin contar, posiblemente, con un cura «tétrico, necio y regañón [...] y si topas con un flojo y regalón, cargará sobre ti todo el trabajo, siendo para él lo pingüe de los emolumentos...» ${ }^{14}$.

En cuanto al Perú se refiere, muchos candidatos pensaban ya que la sola calidad de lenguaraz bastaba para aspirar al estado clerical. En 1792, Lorenzo Soria, de Huánuco, escribía en su solicitud: «...desde que Vuestra Illustrísima avrió la conducta que los lenguaraces pueden ordenarse sin más título que éste, he procurado con más anhelo de ilustrarme tanto en latinidad como en el moral», y en 1799, hablando de sí mismo, Pedro Carrasco, oriundo de la doctrina de Macate (Huaylas), precisaba después de confesar la insuficiencia de su patrimonio para tener la congrua necesaria:

13 Taylor, 1999: vol. 1, 131-133.

14 Fernández de Lizardi, 2006: 64-69. 
... le suplirá por la lengua yndica nativa que rreside en mi persona y que ésta a sido bastante título y caudal en otros candidatos para conferirles dichos órdenes en estos dominios, por ser ella necesaria para darse a entender con los yndios.

Tal afirmación no era una exageración. Ese mismo año, en un edicto que pedía a los candidatos manifestarse, el propio arzobispo había puntualizado:

Los que no tuvieren congrua suficiente para su manutención y que en otro caso desesperarían de poder ingresar en los sagrados órdenes que están para celebrarse en el día, se les franquea caritativamente con la sola calidad [de lengua$\mathrm{raz}]^{15}$.

\section{LAS CONSECUENCIAS DE LAS ORDENACIONES A TÍTULO DE LENGUA}

El manejo de la lengua indígena se había convertido pues en una especie de sésamo para ser ordenado. Entre los candidatos, cierto número de aquéllos que la sabían habían seguido, particularmente en Lima, las clases de algún colegio o del seminario, pero es de notar que progresivamente, hacia finales del siglo, conforme se fueron multiplicando las ordenaciones a título de lengua, el porcentaje de excolegiales o seminaristas fue bajando de manera sensible. Representaban un poco más del $20 \%$ del total en la década de 1780-1789, y sólo alrededor del 15\% durante los últimos cinco años del siglo. La gran mayoría indicaban haberse formado al contacto de algún sacerdote al que habían ayudado, a veces durante un largo período, en su parroquia o doctrina de origen.

No es pues arriesgado pensar que la «oleada» de ordenaciones a título de lengua significó una baja sin duda notable del nivel de los ordenantes. Este problema, quizás nuevo en el Perú, se había discutido algunos decenios antes en Nueva España cuando también allí se había seguido el mismo camino.

En 1766, en su primera carta pastoral al clero secular, el célebre arzobispo Lorenzana había reconocido el valor del conocimiento del idioma indígena, pero afirmó que ese requisito no debía prevalecer en ningún caso sobre las demás cualidades (personales e intelectuales) exigibles de un sacerdote. De no hacerse así, se corría el gran peligro de reclutar para cargos tan importantes a personas no muy adecuadas a su misión, y esto explica por qué el prelado llegó a desalentar ese tipo de ordenaciones. Pocos años después, la misma Corona intervino en el debate con una Real Cédula del 16 de abril de 1770, recordando los requisitos prioritarios que se debían valorar en los ordenandos, re-

15 Expediente de José Norambuena, de la doctrina de Huaraz, 1799. 
quisitos a los que el solo manejo de una lengua indígena no había de anteponerse de ninguna forma ${ }^{16}$.

Otra consecuencia notable fue una modificación profunda del origen regional del clero secular. A comienzos de los años de 1770, los limeños y los costeños, de una manera general, constituían casi la mitad de los candidatos a las sagradas órdenes cuyo lugar de nacimiento y residencia conocemos. Entre 1780 y 1789 , hasta llegaron a más del 60\%. Durante el decenio siguiente, los serranos representaban ya el $66 \%$ de los ordenantes, mientras que los limeños habían bajado a un $22 \%$, y los costeños globalmente al 32\%. La inversión de la tendencia se acentuó aún más a lo largo de los últimos cinco años del siglo, pues los candidatos oriundos de la capital virreinal ya no fueron más que el $22 \%$ del total, correspondiendo otros $6 \%$ a los demás ordenantes costeños.

En las altas tierras andinas de las que procedían ahora la gran mayoría de aquellos que solicitaban las sagradas órdenes, las provincias mejor representadas eran las de la Sierra norte donde «españoles» y mestizos eran proporcionalmente los más numerosos según los censos de la época: Huaylas $(20 \%)$, Tarma/Huánuco (12\%), Conchucos (11\%), hasta en la Sierra central, Jauja con un 5\%. En cambio, las comarcas andinas de la parte sur del arzobispado, tradicionalmente mucho más marginadas y de población más densamente indígena (Yauyos, Huarochirí) parecen haberse quedado fuera de ese movimiento.

Como la lengua índica se había convertido en un elemento central de las candidaturas y estaba pues en el centro de las preocupaciones de los aspirantes al estado clerical, éstos le dedican en sus cartas de solicitud pasajes que consideraban como esenciales, pues constituía, según pensaban, el medio más seguro y eficaz para conseguir aquello a que aspiraban. De lengua de los vencidos, el quechua ya valorizado venía a ser «recomendable», según puntualizan varios candidatos. Insisten - $\mathrm{y}$ es difícil decir si lo hacen con un sentimiento de legítimo orgullo o por mero cálculo circunstancial- que se trata para ellos de su «ydioma natural», o que son «natibo lenguarás» en «la lengua patria índica». Hablan de su «lengua nacional» (esto es de donde habían nacido, materna) indicando que en su región natal «todos usan de este lenguaje», como precisaba Juan Gabriel Herrera, de Huánuco, en 1799.

De lengua vernácula, sin duda despreciada en Lima, el idioma indio se convertía así en el objeto de estudios específicos, al que los candidatos a veces dedicaban esfuerzos particulares por su ya reconocida utilidad y su uso generalizado en la Sierra. Hemos visto el caso de Miguel Tafur, en 1792, pero se podría citar también el de José Felipe Espiridión Huidobro, de Lima, que ha-

16 Taylor, 1999: vol. 1, 133. 
bía aprovechado una larga estancia en la Sierra adonde había ido a curar una tuberculosis, para aprender el quechua. El mismo año, Miguel Núñez, él también limeño, hijo de padres oriundos de España y bachiller en teología, se había formado en esa lengua estudiándola con un racionero de la catedral.

Tampoco faltan candidatos serranos que también indiquen que han hecho el verdadero esfuerzo de estudiar sistemáticamente el quechua y no se han contentado con el conocimiento empírico que les había facilitado su nacimiento y niñez en los Andes (Juan Valentín Navarro, de Oruro, 1790, Ramón Alcayde de Monge, de la Concepción de Jauja, 1790, Cayetano Requena, de Cochas, Cajatambo, 799).

Otros ponían especial énfasis en el hecho de que sabían un idioma muy particular, esto es diferente de la lengua general, y por lo tanto muy útil para la labor con los indígenas de las comarcas donde se practicaba. Podía ser el dialecto de tal o cual región natal (Juan Antonio Bermudes, de San Juan de la Pallasca (Conchucos), 1799), la lengua culle hoy desaparecida, no emparentada con el quechua, y que se hablaba en algunos sectores de la Sierra desde Cajabamba hasta Pallasca (Jerónimo Osorio, de la doctrina de Jauca, Conchucos, y Antonio Bocanegra, de la misma región, 1793), o la lengua chinchaysuyo, esto es el quechua del norte sensiblemente diferente del cuzqueño que se consideraba entonces como la norma (Valentín Tello de Guzmán, Tarma, 1799).

Estos expedientes son también interesantes en lo que concierne al origen étnico de los candidatos. Su pertenencia al mundo indígena ya no planteaba problema. Muchos de los que querían beneficiarse de una ordenación a título de lengua habían nacido en una doctrina, esto es en un medio indígena, por lo menos en aquella época predominantemente indígena, y se especificaba que su partida de bautismo, pieza indispensable en el expediente, se había copiado del libro de los naturales, reservado en principio a los indios, pero entonces también a los mestizos. Esto hacía que a veces el cura de la doctrina juzgaba necesario de precisar que los padres y abuelos del recién nacido eran, sin embargo, «españoles» (Joseph Martín de Solís de las Casas, doctrina de Santa Fe de Hatun Jauja, 1784). Otras veces, una mano anónima, pero sin duda la del párroco, había puesto el mismo añadido (¿o corrección?) en la partida.

El vínculo de ese tipo de «españoles» con la sociedad indígena en que vivían era evidente. Citaremos un caso, entre muchos: las personas que atestiguaron el origen español de Manuel Josef Teodoro de Cazeda y Domínguez, de la doctrina de San Mateo de Huanchor, Huarochirí, en 1791, eran el cacique del pueblo y varios mestizos de apellidos típicamente indígenas.

En la mayoría de los casos de origen mestizo, éste es sencillamente anotado, y no parece haber suscitado reparo de las autoridades episcopales (Fernando Palacios, Huyalas, 1780, Josef Marí Diestra, Santo Domingo de Jauja, 
1784, Jerónimo Osorio, Conchucos, 1792, Mnuel de Orué, Conchucos, 1793, Agustín de la Rosa Sánchez, de Hatun Huaylas, declarado misto en 1797, Manuel Jorge Tamarís, de la doctrina de San Ildefonso de Caraz, Juan Antonio Bermudes, de San Juan Bautista de la Pallasca, 1799, sobre el cual nada está especificado, pero cuyos dos padres son especificados como mestizos.

Como muchas veces en aquella época, la determinación étnica era sujeta a no pocas incertidumbres o borrosidades. Era el caso en 1799 de Antonio Bocanegra, de la doctrina de Cabana, Conchucos. Su madre se llamaba Marías Juliana Canchas en la partida, pero sus apellidos completos, según otros documentos, eran Canchas Pillao (el segundo notoriamente indio) y no obstante declarada española. En cuanto a Ciriaco Guerrero, de Piscobamba, 1793, del que no se decía nada en especial sobre su origen, era hijo de Jacoba Lunaguanca.

Esas pequeñas maniobras para silenciar u olvidar posibles raíces indígenas no eran propia del arzobispado de Lima. Eran características de una sociedad en la que, a pesar del paso del tiempo y de las notables evoluciones al respecto del mundo colonial a finales del XVIII, el elemento «pigmentocrático» seguía en pie de manera más o menos subliminal. Pero, repitámoslo, el mestizaje ya no parece haber sido, en principio, un obstáculo dirimente para el acceso a las sagradas órdenes.

Como recuerda Scarlett O'Phelan Godoy, una Real Orden de 1769 había indicado que en adelante los seminarios deberían contar entre sus estudiantes con una proporción de indios y mestizos situada entre la tercera y la cuarta parte del total efectivo «para que estos naturales se arraiguen en el amor de la fe católica cuando vean a sus hijos y parientes incorporados en el clero» ${ }^{17}$.

A esa decisión se refería sin duda Timoteo Méndez, oriundo de San Marcos de Llapo, Conchucos, en 1799. Precisaba que tenía parientes «mestizos de indio y español» y que su padre era «cuarterón de español». Solicitaba ser ordenado a título de lengua aunque había estudiado latín y teología moral, pero fundaba también su pedido refiriéndose expresamente a «las Reales Órdenes de $\mathrm{Su}$ Magestad con respecto a los mestizos de español e yndico».

Durante los últimos treinta años del siglo, una docena larga de pretendientes eran hijos de familias de caciques, cifra que llega a más de veinte si incluimos en la lista a aquéllos que declaraban ser hijos de yndios nobles, sin más precisiones ${ }^{18}$. En otros casos, es de notar también que el patrimonio necesario de los candidatos se había constituido, en totalidad o en parte, gracias a la generosidad del cacique de su pueblo o e indios «principales», lo cual prueba que

17 O'Phelan Godoy, 2002: 323.

18 Para las ordenaciones de caciques ya desde mediados del siglo XVIII, v. el artículo ya citado de Scarlett O'Phelan Godoy, y de la misma, 1995: 60-63. 
su familia estaba muy vinculada con él (Ambrosio de Miranda, 1781, San Juan Bautista de la Pallasca, Conchucos, niño español, según el libro de bautismo del pueblo y Gregorio Coronel de Macedo, 1781, Huaraz, hijo de españoles).

Algunos de esos hijos de caciques eran de familias muy acomodadas. Josef Pantaleón Malpartida (1785, San Pedro y San Pablo de Piscobamba, Conchucos) probaba un patrimonio de 16.000 pesos, Gabriel Calquipuma (1773, San Pedro de Tapacocha, repartimiento de Marca, Huaylas) anunciaba él 8.300 pesos. Otros, oriundos de Lima, eran hijos de lo que se podría llamar la aristocracia indígena de la capital. Matías Chávez (1781), nacido en la parroquia de Santa Ana, tenía por padre un coronel del regimiento de mi nación, como él decía. El de Francisco Bruno Cárdenas y Colorado (1781), del Cercado - barrio indígena de Lima - y que había sido estudiante del colegio de San Pedro Nolasco, era capitán de la compañía de fusileros del primer batallón de naturales y además intérprete general del distrito de esta Audiencia, cargo que ejercía asimismo el de Juan de Dios Cárdenas y Vargas (1797) también alcalde ordinario del Cercado, propietario de tiendas y casas en dicho barrio.

Los pretendientes que procedían de regiones andinas podían ser hijos de caciques gobernadores, esto es, de la autoridad máxima entre los indígenas a nivel local: Cecilio Ignacio Barba Huaranga o CajaHuaranga según los documentos, estudiante en el colegio San Judas Tadeo de Huaraz (1778 para órdenes menores y 1781 para las mayores, San Jerónimo de Pampas, Huaylas), Tomás Collas de Morales (Hatun Huaylas que precisaba «mi calidad es notoriamente distinguida entre los de mi nación, como podré justificar»), Manuel Inocente Yarusparia (1799, doctrina de Aija, Huaylas, que había estudiado gramática en el colegio de Huaraz). En cuanto a Juan Domingo Florencio (1775, San Pedro de Carhuaz) hijo de los caciques del pueblo precisaba, con orgullo, que era «indio noble legítimo descendiente del Inga».

Otros parecen no haber sido de tanta alcurnia: José Túpac Yupanqui que se había formado en el célebre colegio del Príncipe en Lima ${ }^{19}$ (1787) era hijo del cacique «segunda persona» de San Jerónimo de Tunán (Yauyos), Hermenegildo Huamán y Aguilar (1784, Conchucos) exalumno del colegio de San Pablo en Lima y con capellanía era, sólo, hijo de padre y madre indios principales, como Pedro Luis Cusihuallpa (1789, doctrina de Santa María del Valle, Huánuco) que además insistía en su expediente sobre su pobreza, Francisco Cipriano Gómez (1797, Chancay).

19 Sobre el papel de ese colegio en la educación de los hijos de caciques y sus problemas, Alaperrine Bouyer, 2007: cap. 10. En realidad el documento relativo a José Túpac Yupanqui es un pedido de beca para estudiar en el colegio con vista a ser ordenado de menores. 
Algunos inclusive, aunque insisten en su calidad de caciques o emparentados con caciques, aparecen como españoles en otros documentos. Miguel Guerrero (1792, doctrina de San Pedro y San Pablo de Piscobamba, Conchucos) y Ambrosio de Miranda (1781, San Juan Bautista de la Pallasca, Conchucos) figuran como esa «calidad» en su partida de bautismo, y Josef Pantaleón Malpartida (1785, doctrina de San Pedro y San Pablo de Piscobamba) hijo del cacique del pueblo, precisaba que «dichos [sus] padres han sido y son christianos viejos y limpios de toda mala raza y asimismo españoles legítimos y de notoria onradez». Esas citas se deben relacionar con las ambigüedades de la situación y origen de no pocos caciques, así como de lo borroso, incierto y manipulable, en aquella época, de categorías seudoétnicas, como la de español.

En sus solicitudes, ciertos candidatos insisten además sobre el hecho de que su pertenencia al grupo de los caciques era un argumento suplementario y fuerte en favor de su pedido. En 1781, Francisco Bruno Cárdenas y Colorado (de Lima) especificaba que:

Como yndio noble devo goçar de todos los privilegios, exepciones y prerrogativas que Su Magestad se ha servido dispensar a los de mi clase por leyes y cédulas novísimas, señaladamente las de 11 de septiembre de 766, siendo uno de sus capítulos el que los yndios nobles se admitan sin embargo alguno al estado eclesiástico.

Indicaba que esas disposiciones eran efectivas en el Perú desde el 20 de diciembre de 1774. Sin embargo, antes de esa última fecha, en 1773, Gabriel Calquipuma ya había terminado su carta de solicitud, después de enumerar sus méritos, con la siguiente acotación:

El suplicante cuia naturaleza distinguida en qualidad de yndio noble, se hace muy recomendable y meritoria a su pretención mediante el Real amparo con que $\mathrm{Su}$ Magestad favorece a los de esta distinguida clase y naturaleza.

En el expediente, un tío suyo que le había constituido el patrimonio necesario, volvía en una carta sobre ese aspecto de la voluntad real manifestada por une serie de decisiones que tendían a equipara a los caciques con los nobles españoles. Insistía en que los hijos de caciques:

... puedan ser aceptados, a semejanza de cómo debe acontecer con los españoles, a quienes les equipara en cada una de sus clases.

Otros, en cambio, para dar más fuerza a su solicitud se las arreglaban para que el doctrinero la hiciese apoyar por el común del pueblo reunido en la iglesia ${ }^{20}$.

20 V. por ejemplo, lo que escribe Manuel Solórzano, teniente de cura en la doctrina de Marca (Huaylas) a propósito de la candidatura de Manuel Padilla (1793): «El día próccimamente pasado en que concurrieron todos los yndios de los anexsos ha quien advertí la obliga- 
Sin embargo, fue necesario esperar los últimos años del siglo para que un origen indígena popular fuera netamente indicado y no suscitara por ello ningún reparo de la administración episcopal. Ese tipo de aceptaciones debía de existir sin duda desde hacía cierto tiempo. El arzobispado, probablemente, había preferido hacer como si nada y dejar que obrara el tiempo. Los silencios o las omisiones de las partidas copiadas en los libros de las doctrinas, las declaraciones unánimes de los testigos llamados a declarar por los curas - que no engañaban a nadie - sin duda lo habían permitido, tanto más cuanto que la legislación ya no veía en esto ningún impedimento. Pero ¿podía decirse lo mismo de los antiguos prejuicios que por supuesto no habían desaparecido y de las prácticas sociales que seguían tan arraigadas como antes?

En 1798, Matías Ramos, de Pampas y Cajamarquilla (Huaylas) es calificado en su partida de yndio hijo de yndio ordinario, y de una yndia, y en el caso de Lorenzo Franco, de Huancayo, todos los testigos de la doctrina atribuyen a su padre, Francisco Franco Yupari, la calidad índica. Añaden que su madre, María Laso de la Vega era «mestiza y conocida por tal». ¿Otros casos? Pedro Guamanrraga, de San Juan Bautista de la Pallasca (1799), indio según su partida, el mismo año Juan Ignacio (Huata, doctrina de Caraz, Huaylas), también clasificado como yndio.

En cuanto a Tiburcio de los Reyes (1795) bautizado en la catedral de Lima, que había estudiado latín y teología moral, todos, sus padres y parientes eran de ese mismo origen como probaban los documentos aducidos en el expediente. Él incluso reivindicó esa ascendencia cuando afirmó en su solicitud de ordenación que cumplía con todos los requisitos exigidos: «su legitimidad, nación índica y edad de veinte y cuatros años».

Por supuesto una lectura fina revela prácticas prudentes en cuanto al manejo del origen étnico par algunos candidatos. Hemos visto la omisión del segundo apellido cuando era indígena (práctica que se nota hasta en algunos expedientes de caciques) o la evocación de sólo la parte española de la familia, pero una ascendencia indígena abiertamente afirmada parece no haber sido ya un obstáculo para la ordenación. Además a ese respecto no hemos encontrado las manipulaciones, a veces un tanto burdas, destinadas a veces a ocultarla que se podían constatar en la misma época en el obispado de Arequipa ${ }^{21}$.

De hecho, los pedidos de averiguaciones del arzobispado parecen haberse dirigido sobre todo, al parecer, a indagar eventuales vínculos familiares de los

ción y pena a que encurrían sino manifestaban si lo comprendía alguna cosa de lo contenido en el edicto, halo qual respondieron todos a una vos que nada, antes bien, mui moderado en el hablar, recojido del bullicio y muy aplicado a la yglecia y freqüentar los sacramentos».

21 V. nuestro artículo citado en la nota 8. 
candidatos con el mundo afroamericano. Lo prueba una investigación llevada a cabo por el cura de Huánuco, en 1792, a propósito de un tal Juan Lastra. Lo había declarado descendiente de «españoles legítimos, sin mezcla de zambo, moro, judío ni de otra sexta (sic)», lo cual no dejaba de parecer extraño —y tal vez sospechoso - dado que el texto episcopal, como hemos visto a comienzos de este artículo, no concernía de ningún modo el segundo elemento indicado por el sacerdote 22 .

Los únicos casos documentados - muy pocos además - en los que las respuestas de los curas interrogados por el arzobispo suscitaron una verdadera encuesta revelan a las claras reticencias ante posibles orígenes negros de los candidatos $^{23}$. En 1791, Francisco Pardo, de la doctrina de Tapu, parece haber preocupado bastante al prelado que encargó al doctrinero una indagación que, a diferencia de lo que se solía hacer no fue sólo formal. El doctrinero tuvo que confesar sus dudas en cuanto a la realidad del caso. Al padre del candidato, dice el sacerdote, «unos lo hazen español y otros mestizos», mientras que otros «asientan ser el citado Nicolás Pardo de casta pardo y como que en realidad manifiesta su color y por tal es tenido en la doctrina». Otros, según el sacerdote, no vacilaban en afirmar que el padre era un zambo y de la madre se precisaba «cuya casta no se ha podido averiguar». Como la iglesia de la doctrina se había quemado, ya no era posible remitirse a ningún documento oficial...

Ante lo dudoso de las conclusiones a que llegaba por cuenta propia, el cura convocó oficialmente a nada menos que seis testigos, lo que demuestra que el asunto era para él de importancia. Las respuestas recibidas no aportaron solución alguna porque fueron muy variables, prueba de la dificultad cuando en aquella época se quería establecer con seguridad a qué grupo étnico pertenecía tal o cual persona. Un primer testigo, él mismo mestizo, afirmó que el abuelo paterno de Francisco Pardo era español, lo cual significaba blanco, su abuela mestiza y sus abuelos maternos indios. Otro declarante que se autodefinía como español, había escuchado decir que el abuelo paterno era efectivamente «un hombre blanco» y la madre una mestiza. Una tercera persona (mestiza) dijo a propósito del padre de Francisco Pardo que «éste le pareze mestizo»y que la madre «hera yndia». En fin, otros dos testigos (un mestizo y un indio) confirmaban que el padre del tal vez futuro ordenante era... pardo. En todo

22 Esa investigación «espontánea» de posibles antecedentes africanos entre algunos candidatos también aparece en algunos expedientes de Arequipa. V. Lavallé, 1999: 348.

23 Para la obsesión, en esa época, por indagar orígenes africanos en las partes adversas cuando los demás prejuicios étnicos parecen entonces no pasar a menudo de meros argumentos formales, Lavallé, 2003: 231-252. 
caso, tal vez en vista de lo difícil de la averiguación, Francisco Pardo fue ordenado sacerdote.

Las cosas parecen haber sido más sencillas en contra de Mariano Montes, de Yungay, en 1793. Los testigos de la acostumbrada (y sencilla) encuesta precisaban que el padre de Mariano era «hombre limpio y español conocido». Por esa parte no había pues problema. En cuanto a la madre se la describía «libre dese su nacimiento; siendo una mujer muy blanca y de buen porte». Era pues blanca, eso sí, pero ¿qué significaba la expresión bien extraña para una blanca «libre desde su nacimiento»? Pues el cura que transmitía esos documentos daba la clave.

En una carta muy reservada destinada sólo al arzobispo, mandada aparte, y en la que daba su parecer libremente, esto es fuera de cualquier presión local, el párroco insistía sobre el hecho de que esa familia dejaba mucho que desear. La abuela era «una mulata abatida de bajas obligaciones que después de aber dado a luz a la referida María Barrera [la madre de Montes] se casó con un negro puro». Por si no fuera poco, la tal María Barrera había sido esclava hasta poco antes de su casamiento y era hermana de «zambos esclavos».

La solicitud de Montes al parecer no prosperó, pero las razones tal vez no fueron únicamente étnicas. Por supuesto su padre era «de nacimiento limpio y honrado» pero «de muy mala opinión». Acusado de homicidio, había sido azotado públicamente. Los tíos zambos eran malhechores muertos a balazos o de estocadas. En cuanto al propio solicitante, tampoco estaba exento de reproches. Una mujer le había acusado nada menos que de haber sido corrompida por él.

Es de precisar que los motivos de respuesta negativa del arzobispo a las solicitudes de los candidatos eran en general pocos. Podían fundarse sobre razones médicas. Por ejemplo, en 1773, el diácono Mariano Suárez, de Tarma, que pedía las órdenes mayores desde Lima donde estaba y anunciaba que si las conseguía volvería a su tierra para ayudar a su familia que vivía en un estado de gran pobreza. Enfermo de tercianas, fue rechazado de manera tajante y definitiva («No ha lugar y no se le admita ecepto ni representación sobre el asumpto»).

En general las causas tenían más bien que ver con el pasado personal de los pretendientes. Ese mismo año, a Rafael de Loyola y Lovera, de Ica, en la Costa, se le fue denegada la autorización a pesar de que gozaba de «un patrimonio considerable y capellanía» y había estudiado en un colegio, porque en su respuesta a la encuesta previa el cura del pueblo, confirmado por otros testigos llamados a declarar, había indicado que, según sus antecedentes, no se podía esperar de él nada conforme con las obligaciones de la misión a que pretendía («Ha vivido con libertad [...] nunca ha sido aplicado al estado ecle- 
siástico sino a la mercancía, a lo galeno y al paseo y ésta ha sido la nota de su persona»).

En cuanto a Domingo Víctor de la Vega y Rodíguez, con 35 años, de San Pedro de Carhuas, a pesar de ser, según puntualizaba «mui esperto en la lengua índica que es tan necessaria en este Reyno [...] demás de gozar suficiente patrimonio para ingressar a los órdenes menores como a los mayores» el arzobispo dio un parecer negativo. El motivo fue que se había casado con una india de Santa Olaya (Huarochirí) de la que había enviudado. El solicitante trató, pero en vano, de demostrar que ese casamiento no podía constituir un impedimento: se había casado con ella a los 14 años (esto es sin saber realmente lo que hacía), y sobre todo su esposa «estaba exempta del mundo», como probaba sobradamente el hecho de que, cuando se había unido con ella, a pesar de ser ya viuda de un anterior matrimonio seguía siendo virgen.

Los cambios que tuvieron lugar en el acceso al clero secular peruano a finales del siglo XVIII como en otras partes del Imperio marcan un hito importante en la historia de la Iglesia colonial. Ya preparados sin duda por evoluciones no oficiales pero no obstante reales y concretas en las prácticas anteriores de las ordenaciones, su reconocimiento oficial y las nuevas normas fijadas en vísperas del último decenio del siglo favorecieron, en proporciones importantes en las regiones predominantemente indígenas, la aparición de un verdadero bajo clero.

Más cercano a sus feligreses, y incluso a menudo identificado con ellos por su procedencia geográfica pero también social, cultural y étnica, de formación en no pocos casos más bien limitada, era admitido a las sagradas órdenes con tal que se dedicase exclusivamente al servicio de las doctrinas, sin perspectiva de ascenso ni cambio de destino. Tal evolución tendría consecuencias nada despreciables en el siglo siguiente, pero sin que por eso desapareciera lo esencial del lastre de antiguas costumbres heredadas de la explotación colonial de los feligreses indígenas por sus doctrineros.

Los expedientes examinados son también interesantes desde otro punto de vista. Revelan a las claras en los pequeños poblados del interior andino como en las doctrinas, originalmente y en principio indígenas, la existencia de una sociedad cuyos diversos componentes estaban mucho más compenetrados de lo que se cree generalmente en base a realidades y reglamentos venidos de siglos atrás.

Si bien las tácticas redaccionales de dichos expedientes no carecen de prudencia, de omisiones reveladoras y significantes, a veces de cierta doblez, dan sin embargo una prueba más del hecho de que, en aquella época finisecular, muchas reglas antiguas de la convivencia pluriétnica y jerarquizada ya eran obsoletas por inaplicables dada la tendencia a la porosidad y borrosidad de las 
fronteras internas de una sociedad cuya complejidad, ya muy distante de los encasillamientos estancos que había querido imponer el sistema colonial, se hacía cada vez más contradictoria.

\section{BIBLIOGRAFÍA}

Alaperrine Bouyer, Monique, La educación de las élites indígenas en el Perú colonial, Lima, IFEA-IRA, 2007.

Brading, David, Una Iglesia asediada: el obispado de Michoacán, 1749-1810, México, FCE, 1994.

Estenssoro Fuchs, Juan Carlos, Del paganismo a la santidad, la incorporación de los indios del Perú al catolicismo 1532-1750, Lima, IFEA-PUCP, 2003.

Fernández de Lizardi, José Joaquín, El Periquillo sarniento, México, Editores Mexicanos Unidos SA, 2006.

Ganster, Paul Bentley, A social history of the secular clergy of Lima during the middle decades of eighteenth century, Los Angeles, Univ. of California Press, 1974.

Lavallé, Bernard, «Evangelización y protocriollismo, la cuestión de las doctrinas regulares en el siglo XVI», Las promesas ambiguas, ensayos sobre el criollismo colonial en los Andes, Lima, PUCP-Instituto Riva Agüero, 1993: 63-77.

Lavallé Bernard, «Las doctrinas de indígenas, núcleos de explotación colonial (siglos XVI-XVII)», Amor y opresión en los Andes coloniales, Lima, IFEA-IEP, 1999: 267-289.

Lavallé, Bernard, «Nuevos rasgos del bajo clero en el obispado de Arequipa a finales del siglo XVIII», Las promesas ambiguas, ensayos sobre el criollismo colonial en los Andes, Lima, PUCP-Instituto Riva Agüero, 1993: 331-354.

Lavallé, Bernard, «El argumento de la notoria desigualdad en la relación de pareja (Lima y Quito, siglos XVII-XVIII», Familia y vida cotidiana en América latina, siglos XVIII-XX, Lima PUCP-IFEA, 2003: 231-252.

Lisi, Francesco Leonardo, El tercer concilio limense y la aculturación de los indígenas de Sudamérica, Salamanca, Universidad de Salamanca, 1990.

O'Phelan Godoy, Scarlett, La gran rebelión en los Andes, De Túpac Amaru a Túpac Katari, Cuzco, CBC, 1995.

O'Phelan Godoy, Scarlett, «Ascender al estado eclesiástico. La ordenación de indios en Lima a mediados del siglo XVIII», Incas e indios cristianos, élites indígenas e identidades cristianas en los Andes coloniales, Cuzco, CBC-IFEA, 2002: 311-330.

Taylor William B., Ministros de lo sagrado, sacerdotes y feligreses en el México del siglo XVIII, Zamora, El Colegio de Michoacán-El Colegio de México, 1999, 2 vol. 
Fecha de recepción: 1 de septiembre de 2010

Fecha de aceptación: 6 de octubre de 2010

\section{Towards a new clergy in the Andes at the end of the $18^{\text {th }}$ century: Ordination by way of language in the archbishopric of Lima}

In the archbishopric of Lima, as well as in others, there is a significant change in the recruitment of secular clergy for parishes towards the end of the $18^{\text {th }}$ century. The lenguaraces, those who know the indigenous language, are granted privilege by favoring that prerequisite above all others. This had notable consequences on their preparation, as well as the social and ethnic background of these priests, who were forced to work with a fragile status, with no possibility of relocation or promotion, all of which led to the appearance of a true lower clergy.

KeY words: Parishes; lower clergy; indigenous clergy; mestizo. 